\title{
Communication
}

\section{Chemical fixation of carbon dioxide to cyclic carbonates catalyzed by zinc(II) complex bearing 1,2-disubstituted benzimidazole ligand}

\author{
Jorge L. S. Milani, Igor S. Oliveira, Pamella A. Dos Santos, Ana K. S. M. Valdo, Felipe T. Martins, \\ Danielle Cangussu, Rafael P. Das Chagas* \\ Universidade Federal de Goiás, Instituto de Química, Campus Samambaia, CEP: 74690-900 Goiânia, GO Brazil
}

\section{A R T I C L E I N F O}

\section{Article history:}

Received 3 October 2017

Accepted 1 December 2017

Published 5 February 2018

\section{Keywords:}

Carbon dioxide

Cyclic carbonate

Zinc complex

Benzimidazole ligand

Cycloaddition

Homogeneous catalysis

\begin{abstract}
A B S T R A C T
A new zinc(II) complex of formula $\left[\mathrm{ZnCl}_{2}(\mathbf{L 1})_{2}\right]$ (1) [ $\mathbf{L 1}=$ 2-(2-thienyl)-1-(2-thienylmethyl)-1Hbenzimidazole] was synthesized and fully characterized by nuclear magnetic resonance and infrared spectroscopy, elemental analysis, electrospray ionization high-resolution mass spectrometry, and thermogravimetric analysis. The molecular structure was confirmed by single-crystal X-ray diffraction. Complex 1 consists of mononuclear tetrahedral zinc(II) units with a locked geometry resulting from weak intramolecular $S \cdots \pi$ and $\pi-\pi$ interligand interactions. The benzimidazole ligand and its zinc(II) complex were readily obtained through a simple synthetic route. The catalytic activity of $\mathbf{1}$ was investigated in the coupling of carbon dioxide with epoxides to produce cyclic carbonates, and a series of parameters were evaluated. The complex efficiently catalyzed the transformation of various epoxides under solvent-free conditions, with good conversions, turnover numbers, and turnover frequencies.
\end{abstract}

(C) 2018, Dalian Institute of Chemical Physics, Chinese Academy of Sciences. Published by Elsevier B.V. All rights reserved.
Carbon dioxide is an attractive $\mathrm{C}_{1}$ building block and could provide an inexhaustible, cheap, non-toxic, non-flammable, green source of carbon. Concerns about anthropogenic emissions have aroused interest in the chemical transformation of carbon dioxide, e.g., cycloaddition of carbon dioxide and epoxides to cyclic carbonates [1-4].

Cyclic carbonates have a broad range of applications and are widely used in both industrial and academic areas. This class of compounds can be used as polar aprotic solvents, electrolytes in lithium-ion batteries, valuable organic synthetic intermediates for preparing pharmaceutical, agricultural, and other fine chemicals, and monomers for polycarbonate synthesis [5-7].

The use of carbon dioxide to synthesize organic carbonates through cycloaddition with epoxides (Scheme 1) has the benefits of eliminating phosgene as a reagent and $100 \%$ atom effi- ciency, making it a highly desirable transformation $[8,9]$. However, because of the inert nature of carbon dioxide, a catalytic system is needed to make this process feasible. In recent decades, many homogeneous and heterogeneous catalysts have been developed for this purpose, such as ionic liquids [10-13], quaternary ammonium and phosphonium salts [14-16], metal salts [17-19], metal oxides [20,21], metal-organic frameworks [22], bifunctional catalysts [23-25], and others [8,26]. Among homogeneous catalysts, salen complexes of various metals, e.g., aluminum, chromium, cobalt, and zinc, have been used to catalyze cycloaddition of carbon dioxide to cyclic carbonates [27-30].

A number of zinc-based heterogeneous and homogeneous catalysts have been reported [31-40]. However, many of them either require complicated synthetic strategies, or involve sol-

\footnotetext{
* Corresponding author. Tel: +55-62-3521-1199; Fax: +55-62-3521-1167; E-mail: rafael.pchagas@gmail.com

This work was supported by Fundação de Amparo a Pesquisa do Estado de Goiás (FAPEG 201610267001033) and Programa de Pós-Graduação em Química/Instituto de Química/Universidade Federal de Goiás (PPGQ/IQ/UFG).

DOI: 10.1016/S1872-2067(17)62992-9 | http://www.sciencedirect.com/science/journal/18722067 | Chin. J. Catal., Vol. 39, No. 2, February 2018
} 


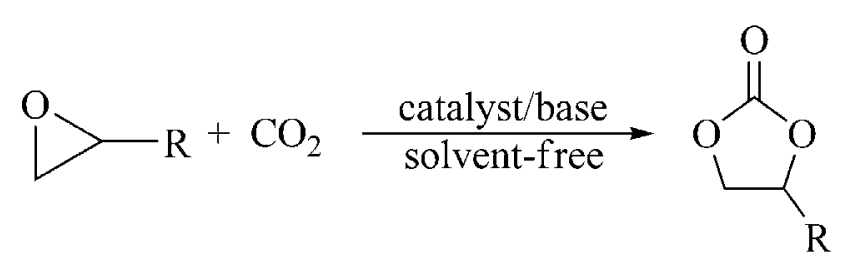

Scheme 1. Cycloaddition reaction of $\mathrm{CO}_{2}$ and epoxides.

vents and/or harsh conditions in the catalytic system, or show low catalytic activities.

Although a variety of ligands have been used to synthesize active metal complexes for the chemical fixation of carbon dioxide, the use of 1,2-disubstituted benzimidazole ligands has not been reported. Benzimidazole-metal complexes have been studied because of their diverse properties, including catalytic activities, and their potential applications as functional materials in electronics, magnetism, and optics [41]. Methods for the synthesis of 1,2-disubstituted benzimidazoles frequently require harsh conditions or expensive reactants, usually involving organic solvents and/or complicated procedures. A number of the reported methods have limitations such as low yields and/or poor selectivities, mainly associated with the formation of 2-substituted benzimidazoles and other side products $[42,43]$.

The development of well-defined, easily prepared, and highly efficient catalysts remains a relevant research topic. In the present communication, we report a simple and inexpensive procedure for synthesizing a 1,2-disubstituted benzimidazole ligand and its use to readily produce and isolate a new zinc(II) complex of formula $\left[\mathrm{ZnCl}_{2}(\mathbf{L 1})_{2}\right]$ (1) $[\mathbf{L 1}=$ 2-(2-thienyl)-1-(2-thienylmethyl)-1H-benzimidazole]. The complex was fully characterized. Its efficiency as a catalyst in the coupling of $\mathrm{CO}_{2}$ and various epoxides to give cyclic carbonates under solvent-free conditions was evaluated; it showed high selectivity and good catalytic activity.

Our group has been working on the development of a simple method for selectively synthesizing 1,2-disubstituted benzimidazoles. The reaction between $o$-phenylenediamine and two equivalents of an aldehyde in aqueous hydrochloric media at $50{ }^{\circ} \mathrm{C}$ produces the corresponding 1,2-disubstituted benzimidazoles in high yields in $30 \mathrm{~min}$. In this work, 2-(2-thienyl)-1-(2-thienylmethyl)-1 $H$-benzimidazole (L1) was synthesized in $90 \%$ yield (Scheme 2 ). The product precipitated in the reaction medium as a brownish solid, which was purified by recrystallization from ethanol to give an analytically pure compound. Ligand $\mathbf{L 1}$ was fully characterized using ${ }^{1} \mathrm{H}$ and ${ }^{13} \mathrm{C}\left\{{ }^{1} \mathrm{H}\right\}$ nuclear magnetic resonance (NMR) and infrared (IR) spectroscopy, and elemental analysis. This method was suc-

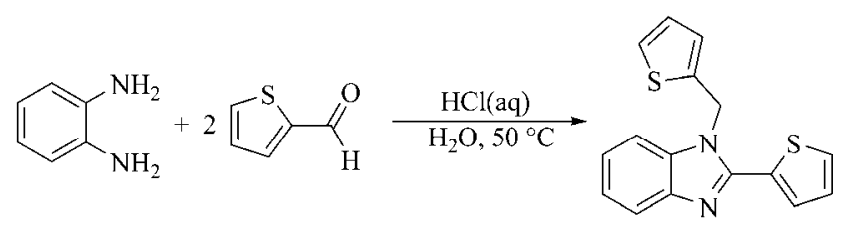

L1, $90 \%$

Scheme 2. Synthesis of benzimidazole ligand $\mathbf{L} 1$.

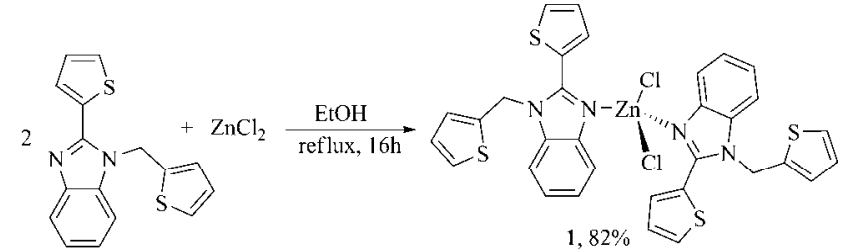

Scheme 3. Synthesis of zinc(II) complex 1.

cessfully used with various aldehydes, and its scope is still being extended.

The reaction between zinc(II) chloride and two equivalents of $\mathbf{L 1}$ in ethanol furnished the corresponding complex $\mathbf{1}$ as a pale-yellow solid in $82 \%$ yield (Scheme 3). Complex 1 was fully characterized by ${ }^{1} \mathrm{H}$ and ${ }^{13} \mathrm{C}\left\{{ }^{1} \mathrm{H}\right\}$ NMR and IR spectroscopy, elemental analysis, electrospray ionization high-resolution mass spectrometry, and thermogravimetric analysis. Single crystals of $\mathbf{1}$ were obtained by recrystallization from acetonitrile and the molecular structure was confirmed by single-crystal X-ray diffraction.

A well-shaped single crystal of $\mathbf{1}$ was selected from the crystallization batch for X-ray diffraction data collection at room temperature (Table S1, Supporting information). Complex $\mathbf{1}$ consists of two units of $\mathbf{L} \mathbf{1}$ and two chloride ions coordinated to zinc(II) (Fig. 1). These ligands form a tetrahedral coordination sphere with the metal ion, with metal-ligand distances of $2.038(4)$ to $2.2570(15) \AA$, and angles of $104.54(12)^{\circ}$ to $113.43(13)^{\circ}$. A slight deviation from perfect tetrahedral geometry occurs in $\mathbf{1}$, as previously reported for similar Ni(II) [44], $\mathrm{Cd}(\mathrm{II})$, and $\mathrm{Hg}(\mathrm{II})$ [45] complexes with related benzimidazole and halide ligands. Notably, there are several weak intramolecular contacts between the two benzimidazole ligands in 1, such as $S \cdots \pi$ and $\pi-\pi$ interactions, which lead to a locked geometry for the whole molecule. All the bonds lengths and angles around the metal center in $\mathbf{1}$ are listed in Table S2 in the Supporting information.

Complex 1 was tested as a catalyst in the coupling reaction between $\mathrm{CO}_{2}$ and various epoxides to form cyclic carbonates under solvent-free conditions. The reaction parameters, namely time, temperature, carbon dioxide pressure, and catalyst loading, and a range of cocatalysts were evaluated in reactions with propylene oxide (PO) and styrene oxide (SO). The system was then tested with a series of different epoxides.

In a general procedure, a $300 \mathrm{~mL}$ stainless-steel Parr reactor

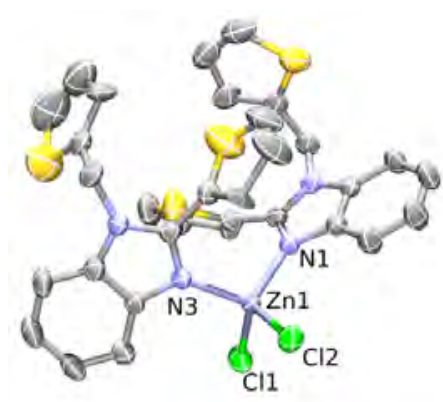

Fig. 1. Asymmetric unit of complex 1 shown as colored atom 50\% probability ellipsoids. 
was charged with complex 1, a cocatalyst, and the epoxide. Carbon dioxide was pressurized into the mixture and the reaction was performed under predetermined conditions. When the reaction was complete, the vessel was cooled to $0{ }^{\circ} \mathrm{C}$ and the pressure was slowly released. The conversion was calculated on the basis of the ${ }^{1} \mathrm{H}$ NMR spectrum of the crude reaction mixture.

The results for the reactions with PO are summarized in Table 1 . The initial experiment was performed with tetrabutylammonium bromide (TBAB) as the cocatalyst. The results show that this catalytic system was active after $6 \mathrm{~h}$, and gave $60 \%$ PO conversion to the corresponding cyclic carbonate (selectivity $>99 \%$ ) with a turnover frequency (TOF) of $248 \mathrm{~h}^{-1}$ (entry 1). In a control experiment performed with TBAB only, i.e., without catalyst 1 , the conversion was $19 \%$.

When the reaction time with $\mathbf{1}$ was extended, the maximum conversion was $94 \%$ after 24 h (entry 4). However, the highest turnover number (TON) was observed after 48 h (entry 5), when the reaction was conducted with double the amount of PO, indicating good stability of the complex under the reaction conditions. These results indicate that the catalytic species remained active for a long period.

Subtle increases or reductions in the $\mathrm{CO}_{2}$ pressure did not significantly affect the conversion or TOF (entries 6 and 7). In contrast, the temperature had almost linear relationships with the conversion and TOF up to $120^{\circ} \mathrm{C}$ (entries 1, 8-10). At 150 ${ }^{\circ} \mathrm{C}, 93 \%$ was observed (entry 11 ), without loss of selectivity, which confirms the stability of the catalytic species. Inactivation of the catalytic system was observed only at $200{ }^{\circ} \mathrm{C}$ (entry 12), although complex $\mathbf{1}$ is stable at higher temperatures, as confirmed by thermogravimetric analysis (Figs. S9 and S11, Supporting information).

Increasing the amount of catalyst (from $0.04 \mathrm{~mol} \%$ to 0.16 $\mathrm{mol} \%$ ) or of cocatalyst (from $0.04 \mathrm{~mol} \%$ to $0.08 \mathrm{~mol} \%$ ) leads to

Table 1

$\mathrm{CO}_{2}$ cycloaddition reaction using $1 / \mathrm{PO}^{\mathrm{a}}$

\begin{tabular}{lrcrcrr}
\hline Entry & $T /{ }^{\circ} \mathrm{C}$ & $P_{[\mathrm{CO} 2]} / \mathrm{bar}$ & $t / \mathrm{h}$ & Conv. $(\%){ }^{\mathrm{b}}$ & $\mathrm{TON}^{\mathrm{c}}$ & TOF d $^{\mathrm{d}}$ \\
\hline 1 & 100 & 30 & 6 & 60 & 1488 & 248 \\
2 & 100 & 30 & 8 & 87 & 2174 & 272 \\
3 & 100 & 30 & 16 & 89 & 2232 & 140 \\
4 & 100 & 30 & 24 & 94 & 2359 & 98 \\
$5 \mathrm{e}$ & 100 & 30 & 48 & 60 & 2994 & 62 \\
6 & 100 & 20 & 6 & 58 & 1454 & 242 \\
7 & 100 & 50 & 6 & 54 & 1351 & 225 \\
8 & 60 & 30 & 6 & 13 & 330 & 55 \\
9 & 80 & 30 & 6 & 38 & 936 & 156 \\
10 & 120 & 30 & 6 & 85 & 2119 & 353 \\
11 & 150 & 30 & 6 & 93 & 2315 & 386 \\
12 & 200 & 30 & 6 & 8 & 187 & 31 \\
$13^{\mathrm{f}}$ & 100 & 30 & 6 & 69 & 428 & 71 \\
$14 \mathrm{~g}$ & 100 & 30 & 6 & 79 & 1984 & 331 \\
$15^{\mathrm{h}}$ & 100 & 30 & 6 & 10 & 254 & 42 \\
$16^{\mathrm{i}}$ & 100 & 30 & 6 & 40 & 988 & 165 \\
\hline
\end{tabular}

a Unless otherwise stated, the reaction was performed with cat:cocat:PO = 1:1:2500, catalyst 1 (0.04 mol\%), TBAB (0.04 mol\%); ${ }^{\mathrm{b}}$ Conversions determined on basis of ${ }^{1} \mathrm{H}$ NMR spectroscopic analysis; ${ }^{\mathrm{c}} \mathrm{TON}-\mathrm{mol}$ of carbonate produced/mol of 1; ${ }^{\mathrm{d}} \mathrm{TOF}=\mathrm{TON} / \mathrm{h}$; ${ }^{\mathrm{e}}$ cat: cocat:PO = 1:1:5000; ${ }^{\mathrm{f}}$ cat: cocat:PO = 2:1:1250 (0.16 mol\% cat: $0.8 \mathrm{~mol} \%$ cocat); ${ }^{\mathrm{g}}$ cat:cocat:PO $=1: 2: 2500$ (0.04 mol $\%$ cat: $0.08 \mathrm{~mol} \%$ cocat $) ;{ }^{\mathrm{h}} \mathrm{TBACl}$ as cocatalyst; IPPNCl as cocatalyst. higher conversions in both cases (entries 13 and 14). However, the cocatalyst concentration had a more prominent effect on the system, as expected.

The role of the cocatalyst was investigated by conducting an experiment without TBAB; no conversion was observed, in accordance with previous studies [33]. When tetrabutylammonium chloride (TBACl) and bis(triphenylphosphoranylidene)ammonium chloride (PPNCl) were used as cocatalysts (entries 15 and 16), the TOFs were lower than those obtained with TBAB. This can be understood in terms of the nucleophilicities and leaving abilities of the chloride and bromide anions in the cocatalysts, which affect the ring-opening and ring-closure steps, respectively [32].

The results of the catalytic tests using SO are summarized in Table 2. Conversions of up to $100 \%$ were observed, with high selectivities ( $>99 \%$, entry 2). In catalytic tests lasting $6 \mathrm{~h}$, increasing the temperature to $120{ }^{\circ} \mathrm{C}$ gave a maximum conversion of $90 \%$ (entry 4). However, when the reaction was performed at $150{ }^{\circ} \mathrm{C}$ (entry 5), the conversion decreased to $81 \%$, indicating possible inactivation of the system at higher temperatures. The effects of the catalyst and cocatalyst loads and the cocatalyst type were similar to those observed for PO. It is worth noting that after reaction for at least $6 \mathrm{~h}$ at $100{ }^{\circ} \mathrm{C}$ or above, the conversions and TONs were high.

As in the case of the PO system, SO conversion to the carbonate did not proceed without a cocatalyst (i.e., in the presence of complex 1 only). Experiments involving sole use of the bases with SO under standard conditions gave the following conversions: TBAB 32\%; TBAI 73\%; and TBACl 91\%. When only PPNCl was used, a complex mixture of products was formed, without the cyclic carbonate. The conversions with TBAI and TBACl are comparable to those using 1 with TBAB. These results suggest that the reactivity patterns of the bases may change in the presence or absence of a catalyst, and depend on factors such as nucleophilicity, leaving ability, and solvent nature, as previously reported $[46,47]$. Tests with the catalyst precursors in the presence of TBAB gave lower con-

Table 2

$\mathrm{CO}_{2}$ cycloaddition reaction using $1 / \mathrm{SO}^{\mathrm{a}}$

\begin{tabular}{lrrrrr}
\hline Entry & $T /{ }^{\circ} \mathrm{C}$ & $t / \mathrm{h}$ & Conv. $(\%)^{\mathrm{b}}$ & TON $^{\mathrm{c}}$ & TOF $^{\mathrm{d}}$ \\
\hline 1 & 100 & 6 & 84 & 1176 & 196 \\
2 & 100 & 24 & 100 & 1400 & 58 \\
3 & 80 & 6 & 38 & 528 & 88 \\
4 & 120 & 6 & 90 & 1261 & 210 \\
5 & 150 & 6 & 81 & 1129 & 188 \\
$6^{\mathrm{e}}$ & 100 & 6 & 81 & 141 & 24 \\
$7^{\mathrm{f}}$ & 100 & 6 & 89 & 1238 & 206 \\
$8^{\mathrm{g}}$ & 100 & 6 & 23 & 327 & 55 \\
$9^{\mathrm{h}}$ & 100 & 6 & 85 & 1197 & 199 \\
$10^{\mathrm{i}}$ & 100 & 6 & 41 & 576 & 96 \\
11 & 120 & 8 & 93 & 1296 & 162 \\
$12^{\mathrm{j}}$ & 100 & 6 & 54 & 757 & 126 \\
\hline
\end{tabular}

a Unless otherwise stated, the reaction was performed with cat:cocat:SO $=1: 1: 1400$, catalyst 1 (0.07 mol $\%)$, TBAB (0.07 mol\%), $P_{[\mathrm{CO} 2]}=30 \mathrm{bar}$; ${ }^{\mathrm{b}}$ Conversions determined on basis of ${ }^{1} \mathrm{H}$ NMR spectroscopic analysis; c $\mathrm{TON}-\mathrm{mol}$ of carbonate produced $/ \mathrm{mol}$ of $\mathbf{1}$; d $\mathrm{TOF}=\mathrm{TON} / \mathrm{h}$; e $^{2}$ cat: cocat:SO = 2:1:700 (0.28 mol\% cat:0.14 mol\% cocat $)$; ${ }^{\mathrm{f}}$ cat: $\mathrm{cocat}: \mathrm{SO}=$ 1:2:1400 ( $0.07 \mathrm{~mol} \%$ cat: $0.14 \mathrm{~mol} \%$ cocat $) ;{ }^{\mathrm{g}} \mathrm{TBACl}$ as cocatalyst; ${ }^{\mathrm{h}} \mathrm{TBAI}$ as cocatalyst; ${ }^{\mathrm{I}} \mathrm{PPNCl}$ as cocatalyst; ${ }^{\mathrm{j}} \mathrm{P}_{[\mathrm{CO} 2]}=5 \mathrm{bar}$. 
Table 3

$\mathrm{CO}_{2}$ cycloaddition reaction using 1 with various epoxides. ${ }^{a}$

\begin{tabular}{|c|c|c|c|c|}
\hline Entry & Epoxide & Conv. $(\%)^{\mathrm{b}}$ & $\mathrm{TON}^{\mathrm{c}}$ & TOF d \\
\hline 1 & & 74 & 1852 & 309 \\
\hline 2 & & 100 & 2500 & 417 \\
\hline 3 & & 83 & 4132 & 689 \\
\hline 4 & & 0 & 0 & 0 \\
\hline 5 & & 42 & 1055 & 176 \\
\hline 6 & & 27 & 683 & 114 \\
\hline 7 & & 33 & 458 & 76 \\
\hline
\end{tabular}

a Reactions conditions: cat:cocat:epoxide $=1: 1: 2500$, catalyst $\mathbf{1} 0.04$ $\operatorname{mol} \%)$, TBAB (0.04 mol\%), $T=100{ }^{\circ} \mathrm{C}, P_{[\mathrm{CO} 2]}=30 \mathrm{bar}$, time $=6 \mathrm{~h}$; ${ }^{\mathrm{b} C o n}-$ versions determined on basis of ${ }^{1} \mathrm{H}$ NMR spectroscopic analysis; c $\mathrm{TON}-$ mol of carbonate produced $/ \mathrm{mol}$ of $\mathbf{1} ; \mathrm{d}$ TOF $=\mathrm{TON} / \mathrm{h}$.

versions: ligand $\mathbf{L 1} 38 \%$ and $\mathrm{ZnCl}_{2} 46 \%$ (with side products).

Complex 1 was then tested in the cycloaddition of carbon dioxide with a series of epoxides, under the standard conditions (Table 3). Except for cyclohexene oxide (entry 4), all the epoxides were converted to their corresponding cyclic carbonates with high selectivity (>99\%) and reasonable to good catalytic activity. The steric effect of the epoxide plays a predominant role in this reaction; the lower the steric effect the higher the activity. Conversions were up to $100 \%$, for the epoxide glycidol (entry 2). Our system also converted $83 \%$ of an epoxide containing two oxirane groups to the corresponding bis(cyclic carbonate) (entry 3). This is significant because diand poly-functional cyclic carbonates can be used in alternative green methods for non-isocyanate polyurethane synthesis, and studies of the use of carbon dioxide for their synthesis have recently intensified $[48,49]$.

In summary, the new dichloro-
bis[2-(2-thienyl)-1-(2-thienylmethyl)-1H-benzimidazole]zinc(II ) complex 1 was synthesized and completely characterized. The synthetic routes for both the ligand and complex are simple and inexpensive. Complex $\mathbf{1}$ is an efficient and robust catalyst for the coupling of $\mathrm{CO}_{2}$ and various epoxides, including one containing two oxirane groups, to give cyclic carbonates, under solvent-free conditions. Complex $\mathbf{1}$ gives high selectivity and has good catalytic activity.

\section{Acknowledgments}

Jorge L. S. Milani, Igor S. Oliveira and Pamella A. Dos Santos thank the Coordenação de Aperfeiçoamento de Pessoal de Nível Superior (CAPES) and FAPEG for fellowships.

\section{Supporting Information}

Supporting information related to this article follow attached. All experimental details are displayed in Supporting information. Crystallographic information file (CIF file) was deposited with Cambridge Crystallographic Data Centre (CCDC) under deposit code 1566034.

\section{References}

[1] M. Aresta, Carbon Dioxide as Chemical Feedstock, Wiley-VCH, Weinheim, 2010.

[2] M. Aresta, Carbon Dioxide Recovery and Utilization, Kluwer Academic Publishers, Dordrecht, 2003.

[3] C. Maeda, Y. Miyazaki, T. Ema, Catal. Sci. Technol., 2014, 4, 1482-1497.

[4] I. Omae, Catal. Today, 2006, 115, 33-52.

[5] A. A. G. Shaikh, S. Sivaram, Chem. Rev., 1996, 96, 951-976.

[6] J. H. Clements, Ind. Eng. Chem. Res., 2003, 42, 663-674.

[7] T. Sakakura, K. Kohno, Chem. Commun., 2009, 1312-30.

[8] M. North, R. Pasquale, C. Young, Green Chem., 2010, 12, 1514-1539.

[9] S. Fukuoka, M. Kawamura, K. Komiya, M. Tojo, H. Hachiya, K. Hasegawa, M. Aminaka, H. Okamoto, I. Fukawa, S. Konno, Green Chem., 2003, 5, 497-507.

[10] J. M. Sun, S. I. Fujita, M. Arai, J. Organomet. Chem., 2005, 690,

\section{Graphical Abstract}

Chin. J. Catal., 2018, 39: 245-249 doi: 10.1016/S1872-2067(17)62992-9

\section{Chemical fixation of carbon dioxide to cyclic carbonates catalyzed by zinc(II) complex bearing 1,2-disubstituted benzimidazole ligand}

Jorge L. S. Milani, Igor S. Oliveira, Pamella A. Dos Santos, Ana K. S. M. Valdo, Felipe T. Martins, Danielle Cangussu, Rafael P. Das Chagas *

Universidade Federal de Goiás, Instituto de Química, Campus Samambaia, Brazil

A $\mathrm{Zn}(\mathrm{II})$-benzimidazole complex is an efficient and robust catalyst for the coupling reaction between $\mathrm{CO}_{2}$ and various epoxides. The synthetic routes for both the ligand and the complex are simple and inexpensive.

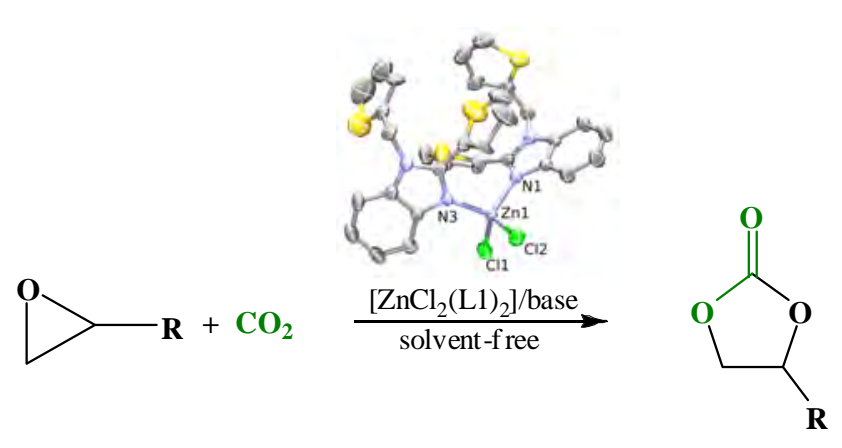


3490-3497.

[11] S. J. Zhang, Y. H. Chen, F. W. Li, X. M. Lu, W. B. Dai, R. Mori, Catal. Today, 2006, 115, 61-69.

[12] T. Chang, X. R. Gao, L. Bian, X. Y. Fu, M. X. Yuan, H. W. Jing, Chin. J. Catal., 2015, 36, 408-413.

[13] S. H. Duan, X. Y. Jing, D. D. Li, H. W. Jing, J. Mol. Catal. A, 2016, 411, 34-39.

[14] V. Calo, A. Nacci, A. Monopoli, A. Fanizzi, Org. Lett., 2002, 4, 2561-2563.

[15] A. Baba, T. Nozaki, H. Matsuda, Bull. Chem. Soc. Jpn., 1987, 60, 1552-1554.

[16] T. Chang, H. W. Jing, L. L. Jin, W. Y. Qiu, J. Mol. Catal. A, 2007, 264, 241-247.

[17] J. W. Huang, M. Shi, J. Org. Chem., 2003, 68, 6705-6709.

[18] H. Kisch, R. Millini, I. J. Wang, Chem. Ber., 1986, 119, 1090-1094.

[19] T. Chang, M. Wu, L. L. Jin, H. W. Jing, W. Y. Qiu, Chin. J. Catal., 2007, 28, 404-406.

[20] M. Ramin, N. van Vegten, J. D. Grunwaldt, A. Baiker, J. Mol. Catal. A, 2006, 258, 165-171.

[21] T. Yano, H. Matsui, T. Koike, H. Ishiguro, H. Fujihara, M. Yoshihara, T. Maeshima, Chem. Commun., 1997, 1129-1130.

[22] M. H. Beyzavi, R. C. Klet, S. Tussupbayev, J. Borycz, N. A. Vermeulen, C. J. Cramer, J. F. Stoddart, J. T. Hupp, O. K. Farha, J. Am. Chem. Soc., 2014, 136, 15861-15864.

[23] T. Chang, L. L. Jin, H. W. Jing, ChemCatChem, 2009, 1, 379-383.

[24] D. S. Bai, X. X. Wang, Y. Y. Song, B. Li, L. L. Zhang, P. Yan, H. W. Jing, Chin. J. Catal., 2010, 31, 176-180.

[25] X. Jiang, F. L. Gou, F. J. Chen, H. W. Jing, Green Chem., 2016, 18, 3567-3576.

[26] G. W. Coates, D. R. Moore, Angew. Chem. Int. Ed., 2004, 43, 6618-6639.

[27] X. B. Lu, Y. J. Zhang, B. Liang, X. Li, H. Wang, J. Mol. Catal. A, 2004, 210, 31-34.

[28] R. L. Paddock, S. T. Nguyen, J. Am. Chem. Soc., 2001, 123, 11498-11499.

[29] R. L. Paddock, S. T. Nguyen, Chem. Commun., 2004, (14), 1622-1623.

[30] Y. M. Shen, W. L. Duan, M. Shi, J. Org. Chem., 2003, 68, 1559-1562.
[31] S. X. He, F. L. Wang, W. L. Tong, S. M. Yiu, M. C. W. Chan, Chem. Commun., 2016, 52, 1017-1020.

[32] W. L. Wang, C. Y. Li, L. Yan, Y. Q. Wang, M. Jiang, Y. J. Ding, ACS Catal., 2016, 6, 6091-6100.

[33] A. S. Aquino, F. L. Bernard, M. O. Vieira, J. V. Borges, M. F. Rojas, F. Dalla Vecchia, R. A. Ligabue, M. Seferin, S. Menezes, S. Einloft, J. Braz. Chem. Soc., 2014, 25, 2251-2257.

[34] Z. Taşci, M. Ulusoy, J. Organomet. Chem., 2012, 713, 104-111.

[35] A. Decortes, A.W. Kleij, ChemCatChem, 2011, 3, 831-834.

[36] C. Maeda, J. Shimonishi, R. Miyazaki, J. Y. Hasegawa, T. Ema, Chem. Eur. J., 2016, 22, 6556-6563.

[37] M. V. Escárcega-Bobadilla, M. Martinez Belmonte, E. Martin, E.C. Escudero-Adán, A.W. Kleij, Chem. Eur. J., 2013, 19, 2641-2648.

[38] L. F. Xiao, F. W. Li, J. J. Peng, C. G. Xia, J. Mol. Catal. A, 2006, 253, 265-269.

[39] M. Taherimehr, A. Decortes, S. M. Al-Amsyar, W. Lueangchaichaweng, C. J. Whiteoak, E. C. Escudero-Adán, A. W. Kleij, P. P. Pescarmona, Catal. Sci. Technol., 2012, 2, 2231-2237.

[40] R. C. Luo, X. T. Zhou, W. Y. Zhang, Z. X. Liang, J. Jiang, H. B. Ji, Green Chem., 2014, 16, 4179-4189.

[41] J. H. Hei, Y. X. Zhi, Y. Zhen, J. Li, F. X. Zhang, J. Coord. Chem., 2013, 66, 1320-1329.

[42] R. Chebolu, D. N. Kommi, D. Kumar, N. Bollineni, A. K. Chakraborti, J. Org. Chem., 2012, 77, 10158-10167.

[43] J. Y. Wang, N. B. Li, R. H. Qiu, X. H. Zhang, X. H. Xu, S. F. Yin, J. Org. Chem., 2015, 785, 61-67.

[44] N. H. Tarte, H. Y. Cho, S. I. Woo, Macromolecules, 2007, 40, 8162-8167.

[45] M. N. Manjunatha, A. G. Dikundwar, K. R. Nagasundara, Polyhedron, 2011, 30, 1299-1304.

[46] T. Ema, Y. Miyazaki, J. Shimonishi, C. Maeda, J. Y. Hasegawa, J. Am. Chem. Soc., 2014, 136, 15270-15279.

[47] A. Mirabaud, J. C. Mulatier, A. Martinez, J. P. Dutasta, V. Dufaud, ACS Catal., 2015, 5, 6748-6752.

[48] R. J. Wei, X. H. Zhang, B. Y. Du, Z. Q. Fan, G. R. Qi, RSC Adv., 2013, 3, 17307-17313.

[49] J. Steinbauer, A. Spannenberg, T. Werner, Green Chem., 2017, 19, 3769-3779.

\title{
含1,2二取代的苯并咪唑配体的Zn(II)络合物上化学固定 $\mathrm{CO}_{2}$ 转化为环状碳酸酯
}

\author{
Jorge L. S. Milani, Igor S. Oliveira, Pamella A. Dos Santos, Ana K. S. M. Valdo, Felipe T. Martins, \\ Danielle Cangussu, Rafael P.Das Chagas * \\ 戈亚斯州联邦大学化学研究所, 戈亚尼亚74690-900, 巴西
}

摘要: 合成了一种新的 $\mathrm{Zn}(\mathrm{II})$ 配合物 $\left.\mathrm{ZnCl}_{2}(\mathbf{L 1})_{2}\right]$ (1) (L1 为 2-(2-噻吩)-1-(2-噻吩甲基)-1H-苯并咪唑), 并采用 NMR和IR光 谱、元素分析、ESI-HRMS光谱测定和热重分析等对它进行了表征, 其分子结构也由单晶X射线衍射确定. 络合物 1 含有单 核四面体Zn(II)单元, 即所谓的锁定的几何结构, 这源自分子中存在弱的分子间 $S \cdots \pi$ 和 $\pi$ - $\pi$ 配体间相互作用. 通过简易的合 成路线即可制得苯并咪唑配体及其与 $\mathrm{Zn}(\mathrm{II})$ 配合物. 采用 $\mathrm{CO}_{2}$ 与环氧化物耦合生成环状碳酸酯反应考察了 $\mathbf{1}$ 的催化活性, 以 及反应条件的影响. 该配合物在无溶剂条件下可高效催化多种环氧化物的转化, 具有较好的转化率, TONs和TOFs.

关键词: 二氧化碳; 环状碳酸酯; 锌配合物; 苯并咪唑配体; 环加成; 均相催化

收稿日期: 2017-10-03. 接受日期: 2017-12-01. 出版日期: 2018-02-05.

*通讯联系人. 电话: +55-62-3521-1199; 传真: +55-62-3521-1167; 电子信箱: rafael.pchagas@gmail.com 基金来源: 巴西政府研究基金(FAPEG 201610267001033); 戈亚斯联邦大学研究计划; 高层次人才计划和FAPEG奖学金. 本文的电子版全文由Elsevier出版社在ScienceDirect上出版(http://www.sciencedirect.com/science/journal/18722067). 